\title{
Inclusion in Higher Education: Learning Experiences of Disabled Students at Winchester University
}

\author{
Victor K. Kioko ${ }^{1} \&$ Tsediso M. Makoelle ${ }^{2}$ \\ ${ }^{1}$ University of Winchester, United Kingdom \\ ${ }^{2}$ University of Johannesburg, South Africa \\ Correspondence: Victor K. Kioko, University of Winchester, United Kingdom. E-mail: vkiokko@yahoo.co.uk
}

Received: March 4, 2014 Accepted: April 22, $2014 \quad$ Online Published: May 28, 2014

doi:10.5539/ies.v7n6p106 URL: http://dx.doi.org/10.5539/ies.v7n6p106

\begin{abstract}
The qualitative study reported on in this article was motivated by the widely held belief that an inclusive approach to teaching and learning is a productive way of enhancing the participation and achievement of all students. In particular, the study was informed by theories of inclusion and the view that disability as a social construct recognizes the challenges that exist within a social setup. In total, four students and three lecturers participated and the interviews were loosely structured and conversational in order to elicit as much information as possible. The emerging findings were analysed using a rhyzoanalytic approach extracted from the philosophies of difference. The findings suggested that inclusive education in the context of higher education is informed by a complex set of understandings and does not revolve around the mere identification of barriers and associated solutions but involves a whole range of factors. In addition, there is need for continuous reflection among practitioners to make the experiences of all the stakeholders rewarding. Inter-departmental discussions on the best practices should not focus exclusively on disabled students but should include all members of staff as well as the rest of the student population.
\end{abstract}

Keywords: Deleuze, disability, Guattari, higher education, inclusion, inclusive education, rhyzo-analytic

\section{Introduction and Background}

The research on which this article is based explored the experiences of disabled students at the University of Winchester as part of a commitment on the part of the Learning and Teaching Development Unit (LTDU) to improving learning by creating an understanding of student needs. The study was motivated by the belief that an inclusive approach to teaching and learning in higher education is effective in addressing student's educational needs. It sought to offer insights into the lived experiences of both lecturers and students as a discussion basis for informing teaching practices and creating an awareness of the hidden voices of disabled students. The emerging conceptualisations were aimed at improving disabled students' learning experiences by shedding light on the effectiveness of the university's current approach to support. As a result, the university would be expected to reconsider or diversify the current range of support structures for students with disabilities as a basis for a wider institutional approach to support learning in general.

The increasing popularity of inclusive education over the years has led to cultural transformations and the development of new policy agendas to include students at all levels of learning. This has been stimulated partly by various laws such as the Disability Discrimination Act (DDA, 1995) in the United Kingdom (UK) which place emphasis on providing support for disabled students in higher education.

As a result, there has been a large increase both in student numbers and diversity in institutions of higher education in recent years (Tinklin, Riddell, \& Willson, 2004). These changing trends have also witnessed pressure for the provision of inclusive education through amendments to the Disability Discrimination Act (1995). Furthermore, according to the code of practice for the assurance of academic quality and standards in higher education published by the UK Quality Assurance Agency (QAA, 2012), disabled students are an integral part of academic life and their needs ought to be central to the university's mission in the same way that other provisions are. As a result, institutions of higher education have developed innovative ways of supporting student needs; however, the extent to which such arrangements work for students is still debatable because student needs are always in a state of "becoming"- that is, continually evolving. 
Although a growing number of studies focus on disabled students' access to higher education, there is little mention of the individual experiences of students with invisible limitations (Tinklin \& Hall, 1999). Furthermore, some studies tend to privilege particular categories of disabilities at the expense of others. What students are actually saying has not been researched in any systematic way (Healey, Fuller, Bradley, \& Hall, 2006); consequently, the voices of the less researched groups tend to be marginalized even further. For that reason, the research study reported on in this article was deemed important to make their voices heard and to highlight the various aspects of their experiences in higher education. In order to create a framework for conceptualizing the difficulties they faced, the study was informed by Oliver's $(1992,1997,1999)$ social model of disability which holds that barriers to learning are social constructs and not the consequence of some inherent medical deficiency or defect in the student as claimed by the deficit-medical model.

While the social model places much emphasis on transformations, it could be argued that the process of addressing barriers should acknowledge that individual circumstances may also contribute to the on-going controversy between these viewpoints. In part, such a view is informed by the perspective that institutional changes should be reflective of the individual circumstances of disabled students. Although it is almost inevitable to construct simplifying categories in reference to a complicated world, the danger lies in the "reductionist view of the perceived identity and attributed existence of the category" (Minow, 1985, pp. 203-204). For Minow, such a situation is reflective of the lived tensions that are at best conceivable within the dilemma of difference. The dilemma of difference is the "risk of reiterating the stigma associated with assigned difference either by focusing on it or by ignoring it" (Minow, 1985, p. 202). For instance, our attempts to identify and address an aspect of difference might have a pathologizing effect. On the other hand, failing to attend to differences may also be excluding because the normalising effect of this viewpoint could lead to treating students as equals in potential. In Minow's (1985) view, the study necessitated living the "dilemma of difference".

The University of Winchester has a wide and diverse range of support structures for students and in particular for those who are disabled. This makes the teaching and learning processes complex because of the challenges of ensuring that individual needs are met. Amidst this complexity, the possibility of some students experiencing difficulties in their learning cannot be ignored; therefore, there is a need to render their silent voices audible. Listening to the voices of disabled students, as Healey et al. (2006) contend, allows them to express their lived experiences of being students in higher education in order to highlight the hidden barriers they encounter. Therefore, the aim of the research was to identify these voices and to create an understanding of the conditions under which learning takes place. In order to achieve this objective, the research on which this article is based sought to achieve the research aims listed in the next section.

\section{Research Aims}

The study was based on the following research aims:

- To investigate the experiences of disabled students at the University of Winchester in relation to the teaching and learning approaches and current support arrangements offered to them.

- To analyse how facilitative the current support arrangements are in supporting their learning.

- To identify ways in which inclusive learning and social experiences for disabled students can be promoted within the university.

\subsection{Conceptualising Inclusion}

Although inclusion has been at the core of teaching and learning in higher education for some time, universities and colleges are still a far cry from becoming truly inclusive (Barnes, 2007). Most of the challenges are due to contradictory factors in the process of pursuing institutional educational excellence. As a result, institutions of higher education have responded by developing new policy agendas and cultural transformations to create a welcoming environment for disadvantaged and disabled students.

However, institutions respond differently to external pressures, and the extent to which changes are made depends on the core values of the institution and whether there are adequate 'spaces' to accommodate diversity. Therefore, the study reported on in this article engaged with the above issues reflected through the lens of inclusivity - used loosely here as an indicator of the extent to which the university has embraced the ethos of inclusion using data from a small-scale project commissioned by the LTDU, which was aimed at exploring the experiences of disabled students at the University of Winchester.

The findings support the view that inclusion in the context of higher education is a becoming process informed by a complex set of understandings and does not revolve around the mere identification of barriers and their possible solutions. However, for the university to achieve an acceptable degree of overall inclusivity, it has to 
acknowledge the inevitable tension of "the dilemma of difference" (Minnow, 1985). The University of Winchester is generally perceived to be an inclusive institution with a high degree of disabled-student satisfaction with regard to the availability of support and understanding from lecturers. However, since inclusive processes are still becoming (evolving), there is a need to improve interdepartmental communication, re-energise the existing support arrangements, and empower new lecturers to be able to deal with difference.

\section{Research Methodology}

Throughout this qualitative study, the researcher was inspired by the process of becoming, a perspective that highlights the importance of constantly shuttling backwards and forwards in an attempt to create and weave together "lines of flight" within the findings (a line of flight is a creative journey that a researcher follows in an attempt to explore fully all emerging aspects of his or her findings). By adopting this becoming approach as propounded by Deleuze and Guattari (1987), the researcher can accommodate new possibilities and organise the research in such a way that the participants are treated as people who are genuinely trying to engage in a process of knowledge production.

As a result, the researcher and the researched become so entwined that conventional hierarchies are destroyed. This orientation means that interviews are dialogic and open up possibilities for other becomings, as the research uses areas of inquiry that allow relations and lines of flight to be followed (Honan, 2007). Rather than clinging to a set of questions, a rhyzomaticc orientation allows the researcher to work within areas of inquiry and frame questions without losing sight of what is salient to the focus and to follow emerging lines of flight that revolve around the research aims (Anyon, 2009).

In line with the overall research approach, the analysis of the data gathered in the course of the research on which this article is based was guided by a theoretical framework within an interpretative paradigm (Yin, 2003; Stake, 2006). A mixed-method approach to analysis, which entwined thematic analysis and a rhyzoanalytic framework extracted from the work of Deleuze and Guattari (1987) was used to analyse and interpret the research findings. A thematic approach helped to identify common themes. By contrast, rhyzo-analysis, a meaning-making concept which contrasts with understanding based on hierarchical logic and cause-effect relations, was applied to establish connections in the findings. Rather than ascribe "hard facts" to situations, this approach describes 'multiple and shifting truths' that are open to becoming (McNaughton, 2004, p. 92).

In describing the structure of a tree, Deleuze and Guattari (1987) advance a form of knowledge conception which is represented as arborescent and hierarchical. To critique this dominant structural approach to thought (the tree logic), the authors illustrate how a binary logic proceeds from the roots, trunk, branches and leaves in fixed linearity. Based on this, they propose a new understanding, building on the structure and functioning of a rhizome which proceeds horizontally, making ceaseless connections. Unlike trees, which have identifiable structures, rhizomes lack beginnings or ends and have the ability to connect in ways that are chaotic and seemingly impossible. The rhizome grows horizontally (not necessarily in a hierarchical manner) and has the capacity to rupture and sprout differently following lines of flight (Deleuze \& Guattari, 1987, p. 10). In essence, the approach is part of an attempt to resist a tree-like account of research that begins at the ground with 'roots ... [then] branches of theory and method would grow from the solid trunk of "the literature" in order to feed the leaves, flowers and fruit of "analysis, interpretation and conclusions" (Leafgren, 2007, p. 35).

Owing to scope and time limitations, the study drew upon a single qualitative data collection technique: interviews. All interviews were audio-recorded and transcribed. The first phase of the research involved dealing with procedural aspects as stipulated by the University of Winchester through which ethical aspects were identified and addressed. This meant that, apart from applying for research authorisation, the gatekeeper of students with disabilities was involved in identifying and recruiting participants. Due to the large number of research projects taking place at that time, it was decided that invisible limitations were under-researched and a sample of students from three categories were approached for inclusion in the study (visual, hearing and chronic illnesses).

The gatekeeper sent out project information sheets and consent forms to the parties concerned. However the rhyzomatic nature of the research ensured that it was receptive to new openings and ready to follow emerging lines of flight. For instance, a large number of students were expected to respond due to the promise of an Amazon reward; consequently, it was assumed that a diverse sample could be selected. However, owing to unforeseen circumstances and the timing of the project, there was a great disparity between the expectations and reality.

The sampling criterion for the study was purposive. Thus, research subjects were selected on the basis of the richness of information related to the inquiry. In liaison with the gatekeeper, mainly students with invisible 
limitations were targeted and four of them from different departments agreed to take part in the study. Three lecturers from different faculties were identified and approached directly. As Silverman (2000) asserts, giving appropriate thought to potential ethical dilemmas and obtaining relevant consent are essential before data collection. Therefore, after the participants had been identified, informed consent was sought by giving detailed information about the project. Moreover, the volunteers were asked to sign a consent form which further outlined the research agenda, their rights, and the benefits and anonymity of the information they provided.

However, the research was carried in full awareness of the ethical dilemmas involved in conducting research with human beings. This necessitated an orientation of becoming which assisted the researchers in being ready to face any uncertainties by being ethically mindful (West, 2002). There was also an attempt to incorporate an awareness of the busy nature of university students and staff routines; therefore, interviews and observations were arranged so as to cause minimal disturbance.

Given the crucial importance of participant confidentiality and anonymity, all the recorded items were transcribed and the data were stored securely. Moreover, all participants were given pseudonyms to conceal their identity, and any other information that could identify them was changed.

Despite the promise of an Amazon.com voucher as an incentive for participation, only four students returned the consent forms. Two of the respondents were partially sighted, whereas one was totally deaf, although she had benefitted from assistive technology from an early age and could function normally within the hearing world as long as she wore hearing aids. Without them, it would be impossible to hear even the sound of a fire alarm, she said. The fourth student, who was physically disabled, disclosed her disability as Friedrich's ataxia (an inherited disease which causes progressive damage to the nervous system, resulting in symptoms ranging from gait disturbances to speech problems; and which could also lead to heart disease and diabetes). All the students had the use of a note-taker and sometimes used dicta phones to record lectures. Three lecturers from two faculties also participated in the study.

Although the findings can be construed as a reflection of seven voices, the study recognizes the multiplicity in each of them and thus a myriad of voices. This follows the consideration of the multiplicities in each of the voices and the multiplying effect they had on the researcher and on prospective readers. This follows the Deleuzoguattarian notion that, in writing A Thousand Plateaus, Deleuze and Guattari (1987) constituted a crowd because each of them was several. Thus:

[Rather than analyzing the data into] discrete components reducing their manyness to the one of identity, and ordering them by rank, [rhyzo-analysis] ... synthesizes a multiplicity of elements without effacing their heterogeneity or hindering their future potential for rearranging (p. xiii).

Despite a becoming attempt to incorporate philosophies of difference in making sense of the findings, there was the inescapable tension of getting caught up in the complexities of doing research using conventional approaches to research (Allan, 2008). However, as Scheurich (1997) contends, it is almost impossible to escape from such a tension because:

... even radical researchers who have questioned the deep rules and assumptions in education research still audiotape, systematically code, and do pattern or thematic analysis of data. These latter practices are the practices of reason and they are assumed to accord with a researcher-trained mind (cited in St. Pierre \& Pillow, 2000, p. 10).

\section{Discussion of the Findings}

The experiences of students are different despite the efforts to include them, because they record varying degrees of satisfaction. Thus, the findings incorporate the various connections of voices and views of the participants, as well as the researcher perspectives enriched by the whole research experience. However, three lines of flight become noticeable: learning and teaching experiences; learning and examination support; and good relationships and effective communication.

\subsection{Learning and Teaching Experiences}

The university was generally viewed positively in terms of the range of support students with disabilities receive. Student participants expressed a high degree of satisfaction with regard to their learning experiences and commended the hard work of the lecturers and the university organization for the support they received. Lecturers were also satisfied with how students were supported, despite their asking for more assistance (as indicated in the following three excerpts): 
Participant 1: So, generally I have had technological support and in terms of other disability support I've got here in terms of staff, they kind of ask you, 'What can we do to help?' and they are very accommodating. They tend to find ways of supporting in terms of what is available... if you provide a list of what you need for your support, it's always easier for the disability team to guide you accordingly.

Participant 2: Basically, if there was a student who was unable to undertake a certain task, we would find them another task and to do that I would inform the programme leader and work out with them what best can be done in that situation ... so that's it, so we can really do it.

Participant 3: Yeah, I have a mentor that I see, and we go through things.

The level of support and experience at the University of Winchester was further elaborated on by participant 1 , who compared her experiences to other UK universities that ranked high on the "league table":

Participant 1: Interestingly, I went to [the] university of [name omitted] for my undergraduate studies]. They are one of the foremost leaders in the education of deaf students in the country. And they have a substantial community of deaf students but, interestingly, their support there was about access ... disability awareness is predominantly for students with ... I mean, comparing that experience to here ... is very much ... is more specialised in terms of disability awareness whereas here [Winchester] is much more diverse to other disabilities which is absolutely fine.

Despite the widespread satisfaction with the University of Winchester, having an elaborate support system to enhance a positive learning experience is not enough because not everyone is able to take advantage of it: As participants 1 and 4 pointed out, there is a great deal of personal effort and confidence involved in facilitating a student's inclusion because support can only be rendered once interest has been expressed:

Participant 1: I think so because, you know, I've been going for job interviews recently ... and I'm ... what I find is that people are very willing to accommodate you, but they need to know!

Participant 4: I know - I mean if, I personally, if you want something, you have to go get it yourself and you can't sort of expect automatically someone to ...

Confidence has the potential to overcome barriers and can be fostered by encouraging students to come forward to talk about their disability openly. Although it is not always possible for all students to be confident enough to do so, participant 1 maintained that confidence had been fundamental in her pursuits. She substantiated her statement by giving an account of previous experiences while attempting to gain admission:

Participant 1: ... when I went for the interview and explained to the tutors about the equipment I use, they said, 'Oh, that's interesting, fine that's ok.' Then when I went for a presentation and said to them, 'Oh please could you wear it, ...' I got extreme responses: 'What on earth is that, what do you want me to do?'

Researcher: That must have been strange...

Participant 1: Of course, because I felt as though I had to apologise for my disability... otherwise if I didn't bother talking about my disability, I would have just sat there and not hear anything .... I had such a negative experience from that interview. It was like they were saying that we are too mighty to worry about meeting students' needs. I then told my parents and tutors that if I got an admission, I would definitely turn it down because I had such a bad experience.

Lecturers also expressed some level of satisfaction with regard to their ability to teach a diverse range of students owing to the communication they received from their departments. However, this experience as discussed in sub-section 4.3 (Good Interpersonal Relationships and Communication) is not always the same, especially for early career lecturers.

Lecturers admitted that they received emails regarding disabled students in their subject groups. However, there was a case in which a lecturer expressed doubt about not being made aware of what his responsibilities were towards particular categories of disabled persons. In fact, the lecturer admitted that, even when he was supporting students to accomplish tasks, the lack of knowledge about a specific disability, for example, posed challenges. It was thus felt that, while it was a lecturer's responsibility to be adequately prepared to achieve the teaching objectives, emails sent out regarding students with disabilities ought to have some details about the nature of the disability and perhaps what an "expert" would do to help. Such a knowledge base might even stimulate lecturers to conduct more research and prepare lectures with the student in mind, as argued by participant 2: 
When the emails are sent out disclosing the students' disabilities, maybe, there could be an advisory about how to teach them, addressing each disability-that, would be very helpful. It might not be enough but quite important ... that would be helpful if the information can be relayed through the departmental administrator - but I don't know where that would come from.

Despite the elaborate support system within the university and the various organs that strove to facilitate learning, students reported incidences where they felt excluded. For instance, despite having written to her department in advance about her accessibility needs, participant 4 reported that lectures would sometimes be conducted in inaccessible rooms, which meant that she would miss the lecture.

Participant1, in turn, pointed out how a disabled note-taker was unable to access a lecture hall, and how some lecturers had failed to incorporate her disability into their planning. Owing to hearing difficulties, she missed out on some video clips played in the lecture. She was, however, happy that such incidences were minimal and that, through her efforts, lecturers were able to provide transcripts of the clips. This arrangement was thought to be beneficial because the effort made to include one student also benefited others.

Although teaching and learning experiences at the university were believed to be commendable, there is no guarantee that all barriers can be eliminated. Thus, there should be a continuous effort to sensitise all the parties concerned about the becoming nature of challenges. Such awareness needs more rigour in the way information about students or supporters is communicated.

\subsection{Learning and Examination Support}

Through the Disability and Learning Diversity team, the university offers an elaborate range of assistance to disabled students in four main areas: Assistive Technology Training, Dyslexia Support, Mentoring and Non-medical Personal Assistance, and Study Skills Support. The presence of yet another support system, Library support, enables students to access learning resources that have a direct link to materials that could enhance their learning. However, all the stakeholders stressed the importance of note-taking in the teaching situation because all student participants had access to note- takers and because notes play an important role in assisting students to prepare for the examinations. For instance, participant 4 was able to record lectures but felt bored having to listen to them over and over again, thus relying more heavily on support from note-takers:

In my course we have to do lots of group work ...so with the dictaphone, I just record because I am slow at writing. I kind of respect my note-taker to write something for me ... I take it with me to record lectures and take it home ... to listen to the lecturer all over again ... I didn't want to keep it, so I just decided to keep it aside and use a note-taker.

However, not all students are able to exploit this range of support fully. This is partly dependent on individual students because personal effort, as highlighted in section 4.1 (learning and teaching experiences), plays a significant role in enhancing full inclusion in the university. For participant 4, it was important to communicate her needs in advance:

I usually send a message at the start of the semester, like a week before, reminding the faculty of my needs assessment, hmm, and that I require a table and an accessible room, yeah.

Nevertheless, it becomes even more difficult for students who might want to hide their disability for fear of being stigmatized as they would be unable to access the much-needed support from the student service cascaded down to their respective faculties. The student participants gave related accounts of negative experiences with note-takers but decided not to take action or inform their departments as they believed that it might affect specific individuals negatively. For instance, participant 3 gave an example of a note-takerwho failed to turn up as expected, thus forcing him to work harder in the lectures.

Hmm, hmm ... actually like last semester, I had one that wasn't good, sometimes didn't turn up. $\mathrm{Hmm}$, in the first year and first term, everything seemed to work ok.

This caused a great deal of frustration because he had to record the lectures and then go through the difficult process of attempting to transcribe them. Participants 1 and 3 remarked that, even when there was a change of note-takers, it was felt as if everything had to start all over again because it meant going through another process of establishing rapport and new working partnerships:

Participant 1: It depends, one of my note-takers was fantastic; she was actively engaged with the lecture and knew what she was writing. The fact that she was a student when I read it, it meant[made] perfect sense and incorporated the ideas in my exams. Well, there was another who tried to write everything that was being said, so it was jangled up and when I try to read it, it 
doesn't make sense. The quality of writing wasn't good and given that they have to spend a lot of money, it wasn't good standard.

Participant 3: In fact I'm having a few problems this year. I'm not working well ... it is hard when you get someone that you are not used to seeing, and you kind of start over again ... yeah.

As emphasized previously, there was also a situation whereby a disabled note-taker could not access a lecture room, thereby forcing the disabled student to take her own 'patchy' notes. However, the student who raised this matter was happy that her suggestions about making buildings barrier-free had been implemented to some extent Since she belonged to the Students' Representative Council (SRC), she could use that forum to express her views about disabled students' experiences.

One of the main issues raised by the students concerned the quality and training of some note-takers or scribes. The participants pointed out that sometimes the note-takers made learning or writing examinations difficult because the notes did not capture the main points, were patchy or difficult to follow. For instance, participant 5 described a situation where the note-taker's notes were inaccurate, poorly written, and wasted much of the student's time when he or she was preparing for the examinations:

... the student found that what the scribe wrote was not accurately representing what they said and thus a lot of exam time was spend correcting errors.

Participant 5, who represented disabled students on various forums, attached importance to this concern and even suggested the need for a different criterion to be used while recruiting note-takers and scribes:

... the note-takers need to be really engaging and able to identify the main points that are being said in the lecture...

Her worries were reflected in the views of students who, commenting on the note-takers, suggested that their subject specialism or abilities should be used in recruiting them, especially in technical subjects. It was suggested that if, for instance, a mathematics note-taker had a background in that subject, they would be able to take quality notes as they would most likely understand what was said in the lecture:

... I think it would be quite interesting to think of - say postgraduate or other students taking notes ... It would actually be a better idea to have students who have some knowledge in the subject they are taking notes...

As suggested, note-takers and scribes play a crucial role in supporting disabled students. The arguments raised point to the importance of having quality note-takers and scribes. That need can only be met if the criteria stipulated that support workers for some subjects should have a technical knowledge base. Student services can, for instance, liaise with relevant departments to ensure that note-takers are appointed from the ranks of students taking courses similar to those of the disabled students or those with technical knowledge.

\subsection{Good Interpersonal Relationships and Communication}

The participants all believed that interpersonal communication and positive relationships are essential. As regards the situation at the University of Winchester, participant 2 stated:

Participant 2: Good staff relationships and good student-staff relationships and communication are quite good because we all support each other...

Participant 3: In fact I'm having a few problems this year. I'm not working well ... it is hard when you get someone that you are not used to seeing, and you kind of start over again ... yeah.

Communication was a key theme in the project because, apart from ensuring that the support needed was made available to students, it facilitated a working relationship between students and staff. This interactive process was viewed as an important ingredient in fostering individual inclusion and realizing the institutional ethos. This implies that even when support systems do not seem to work in harmony, the individual's effort becomes an important factor through communication. However, as stressed in the teaching and learning experiences' findings, not all students have the confidence to talk openly about their disabilities or request for any form of support.

Participants 1 and 4 expressed their confidence in making others aware of their limitations due to their disability and were ready to facilitate their own inclusion. As argued earlier by participant 4 , it would be hard for institutions or people around the disabled person to offer support if they did not know about the individual's needs. She attributed her personal effort in talking about her disability as the key to her success in the workplace and felt that other students ought to take a leading role in facilitating their inclusion. The reason is that, when an individual has an invisible limitation, it is more likely to be excluded from learning activities because people around would not know about the limitation. As a result, communication becomes a very important aspect in all 
efforts towards inclusion, as participant 1 observed:

The thing that I have learnt in school was that it's all about communication and I have always been very lucky, very confident, and very vocal about my disability. I've got a piece of equipment with me which is called ' $v$-link' ... it's like a personal microphone. So I hand it over to a tutor, teacher or lecturer so that when they talk I can pick up their voice...

Whereas student services played an important role in liaising with departments in order to inform them about students with disabilities, communication breakdowns were more likely to happen at intra-departmental level. This was because some departments worked better than others. For instance, participant 5 , who worked in a department where a student participant expressed satisfaction, gave an elaborate account of how the department communicated and made all tutors aware of disabled students in the department:

Err, there is a confidential email with learning agreements for students with disabilities ... it has the name of the students and brief information about the impairment and the need ... the provision they will need for example the texts and font sizes they require or the teacher to wear a hearing loop and [arrange for] extra times in exams. So, that's really up to the teacher to be aware of what mode of support [is needed] and to prepare the relevant materials.

Lecturers know about disabled students mostly through formal mechanisms, or informally when the students approach them. However, these mechanisms do not always give a complete picture about the student because there may be other important aspects that, if known, may impact positively on the way a student is supported. The information relayed can sometimes give the impression that only technical assistance is needed and may portray the student as needing only material modification in the learning process. Thus, in order to enhance proper inclusion, it is important to attach more information about the student and suggest a possible approach for lecturers to use in order to accommodate the student in the learning process. For example, participant 6 remarked:

The adjustments that are important is to make sure that the student can access material, but if there is no relationship in place in which the student is valued as intellectual and not as err... deficient ... err, then really you know education can be gained and that's the point of being here really.

Participant 6 further remarked that students' needs should be looked at beyond individual deficiencies and a deliberate effort should be made by those involved in their education to establish more meaningful relationships. For the participant this was seen as a becoming process that should involve a wholesome approach to discussing matters concerning disability and re-evaluating the current values:

Well, ... let me explain this clearly, the problem comes in when we see disability as a technical issue or something that can be overcome through technology and when we lose sight of the fact that actually a commitment to creating a becoming inclusive environment means thinking much more broadly about who we are, what we value and how we can stop students and staff failing much or feeling excluded. So. the questions around the disabling of certain students' impairments comes not as question of making reasonable adjustments ... but a question of what we value, and what our hopes are.

Including students with disabilities from this perspective then generates a more comprehensive approach than mere a communication about the nature of their disabilities and provides meaningful information that can be used to support them. This might require giving meaningful insights into how to structure teaching and learning experiences to accommodate them. However, it has not always been the case at the university because less experienced lecturers might struggle to meet the students' need, as participant 2 remarked:

Researcher: What is your experience of interacting with students?

Respondent 2: When students come to you, you help them as much as you can. I try to make sure that they are well equipped to tackle the tasks that I teach. So I help to equip them with the knowledge to handle the tasks... how they approach things. But again, I wouldn't know what is expected of students with particular disabilities ... and I have seen no way I would be able to find that out via the institution.

Although knowledge about accommodating students with disabilities does not always imply training lecturers to be experts in all disabilities, experience does play an important role. Two of the participating lecturers pointed out that they had gained experience through training and participation in departmental disability forums and expressed confidence that the university was well placed to share information by allowing other staff. This information sharing process could benefit other staff by giving them access to information about how to cope with certain situations. Perhaps one way of facilitating this process of information sharing is to create an information hub accessible to all and providing more information about a student's learning needs in relation to 
his or disability. This view presupposes constant engagement with other staff and departments because, even when a clear line of communication was established, participants felt that there was room for improvement

Researcher: So, do you have a similar experience here, say, lecturers getting shocked when you hand over your equipment?

Participant 1: It varies, certainly at the beginning of the year, an email is sent out from my department and I am sure they receive the emails about me. So when I approach them, some show an awareness and say, oh, so you are the student! 'I got an email about you' and then wear the equipment. There are others who simply don't read their emails or just ignore them because they don't seem to be aware of my disability and just say, ok, I will wear them ...

The information bank created can then be utilized in the planning of future lectures and being innovative in the way lecturers teach, as participant 5 hinted:

I think from experience, they are incorporated quite well and when I look over when I started, there were students who were finding it difficult working in groups like a lot of ... assignments require a lot of group work. So when they are being in a discussion within the team, we need to think about what can be done to make students more comfortable but still maintain the learning outcome err... is much more of research and I think that we need good practice, ensuring that the students are comfortable in the learning environment while maximising the learning outcome...

There is room for improvement in the way information is communicated because it is an important aspect of facilitating positive learning experiences and providing support. As for students who lack the confidence to disclose their disabilities openly, it was suggested that an effort should be made by student services to make students aware of the available services, and to encourage them to use them. One of the students admitted that she was unaware of the formal procedures for accessing the assistance rendered by student services and mostly relied on her department to arrange for assistance. It was thus suggested that even posters with details about the support available could be an important tool in creating awareness about the services provided.

\section{Suggestions and Implications}

Inclusion in the context of higher learning is multifaceted and not a technological quick fix. It is important to consider the cultural manifestations, to recognise each person as an individual, and to acknowledge that the ideal of constantly reaching out to all might not be realised. While it is evident from the above findings that the university needs to make buildings more accessible, that in itself is not enough. What is needed is a commitment to engage in a process that could lead to a cultural transformation because inclusion cannot be a state. This process of becoming, as suggested, is complex because student demands are diverse and arrangements should be reflective of this and not just assume all is well.

The view that barriers only exist in relation to students was seen as a limited perspective because there was a diverse workforce who were at the risk of being excluded in favour of students only. A lecturer raised concerns that focusing studies on disabled students only was unlikely to create an inclusive culture because staff with disabilities also needed to be included. This suggested a diversification of future research to include staff with disabilities. An important step towards the promotion of inclusion in higher education might therefore be premised on the assumption that everyone was impaired and not just disabled students, because it had the promise of changing the conditions of all (Shakespeare \&Watson, 2003, cited in Healey et al., 2006).

As the study highlighted, there was also a need to focus on able-bodied students because of the concern that they might feel that disabled students were being favoured. This suggests exploring how other students perceive the range of support rendered to their counterparts. As indicated by one of the participants, a wider approach that recognizes individual circumstances is needed to enhance rewarding experiences and create positive relationships. For this to be successful, a deliberate attempt should be made to re-assess the values and needs of all the stakeholders at the University of Winchester, from top management right down to the bottom.

\section{Conclusion}

This small study has made audible some of the voices of disabled students at the University of Winchester. Although it was limited in scope and lacked a strong basis for generalisation, its implications can be useful in improving the inclusivity of the university.

For instance, it is clear that for the teaching and learning experiences of disabled students at the university to be enhanced, issues of access to facilities, communication and personal effort are important. This is because once a need has been identified and information shared about the support required, then it becomes easier for teaching 
staff to anticipate. The process, however, should be reviewed constantly as new needs emerge, which might require a different approach. In the process, an information bank will develop which can be utilised by all staff. In this transformative process, the institution can begin to reposition itself towards an inclusive orientation, thereby accommodating the needs of all. As attempts are made to include the needs of disabled students, cultural transformations are likely to arise, which could lead to the inclusion of the average majority.

Despite the commitment by the university to uphold the various disability laws, the study found that more could be done to improve disabled students' learning experiences. This becoming aspect requires engagement with students and staff in a variety of ways to try and ascertain their actual experiences and what can be done to improve their experiences because, as pointed out previously, inclusion is not a state. There is more to this improvement than the mere facilitation of mobility and arrangements for learning support.

One of the ways to improve disabled students' learning experiences could be to carry out a comparative study with other universities to know how well they have done and to learn from them. While it is true that every institution is unique, there are important lessons to be learned from others. For instance, it is significant that at two internationally well-ranked universities, a student cited positive and negative experiences.

There is also the case of framing research not just to focus on minority groups but also on others because, in trying to accommodate difference, everyone is more likely to feel included. Inclusion and exclusion work together because the inclusion of some inevitably results in the exclusion of others, and vice versa. Thus the institution should be changing while addressing the needs of individual students.

Owing to the timing of the research, the study did not incorporate a larger sample as originally planned. A similar study conducted with a broader range of participants could be useful in bringing in more voices and serve the purposes of triangulation. This could also mean targeting non-academic staff who play a vital role in harmonising the support students receive.

\section{References}

Allan, J. (2008). Rethinking inclusive education: The philosophers of difference in practice. Dordrecht: Springer.

Anyon, J. (2009). Theory and educational research: Toward critical social explanation. New York, NY: Routledge.

Barnes, C. (2007). Disability, higher education and the inclusive society. British Journal of Sociology of Education, 28(1), 135-145. http://dx.doi.org/10.1080/01425690600996832

Deleuze, G., \& Guattari, F. (1987). A thousand plateaus: Capitalism and schizophrenia. Minneapolis, MN: University of Minnesota Press.

Healey, M., Fuller, M., Bradley, A., \& Hall, T. (2006). Listening to students: The experiences of disabled students of learning at university. In M. Adams, \& S. Brown (Eds.), Towards inclusive learning in higher education: Developing curricula for disabled students (pp. 1-12). London: Routledge Falmer.

Honan, E. (2007). Writing a rhizome: An (im)plausible methodology. International Journal of Qualitative Studies in Education, 20(5), 531-546. http://dx.doi.org/10.1080/09518390600923735

Leafgren, S. L. (2007). Reuben's fall: A rhyzomaticc analysis of moments of disobedience in kindergarten ( $\mathrm{PhD}$ thesis, Kent State University College, Kent, $\mathrm{OH}$ ).

McNaughton, G. (2004). The politics of logic in early childhood research: A case of the brain, hard facts, trees and rhizomes. The Australian Educational Researcher, 31(3), 87-104. http://dx.doi.org/10.1007/BF03249530

Minow, M. (1985). Learning to live with the dilemma of difference: Bilingual and special education. Law and Contemporary Problems, 48(2), 157-211. http://dx.doi.org/10.2307/1191571

Oliver, M. (1992). Changing the social relations of production.Disability. Handicap and Society, 7(2), 101-114. http://dx.doi.org/10.1080/02674649266780141

Oliver, M. (1997). Emancipatory research: Realistic goal or impossible dream? In C. Barnes, \& G. Mercer (Eds.), Doing disability research (pp. 15-31). Leeds: The Disability Press.

Oliver, M. (1999). Capitalism, disability and ideology: A materialist critique of the normalization principle. In R. J. Flynn, \& R. A. Lemay (Eds.), A quarter-century of normalization and social role volarization: Evolution and impact (pp. 163-174). Ottawa: University of Ottawa Press.

QAA (The Quality Assurance Agency). (2012). Safeguarding standards and improving the the quality of UK 
higher education. Retrieved March 10, 2012, from http://www.qaa.ac.uk/Pages/default.aspx

Scheurich, J. J. (Ed.). (1997). Research method in the postmodern. London: The Falmer Press.

Silverman, D. (2000). Doing qualitative research: A practical handbook. London: Sage.

St. Pierre, E. A., \& Pillow, W. S. (Eds.). (2000). Working the ruins: Feminist poststructural theory and methods in education. New York, NY: Routledge.

Stake, R. E. (2006). Multiple case study analysis. New York, NY: Guilford.

The National Archives. (1995). Disability Discrimination Act 1995. Retrieved March 10, 2012, from http://www.hmso.gov.uk/acts/acts1995/1995050.htm

Tinklin, T., \& Hall, J. (1999). Getting round obstacles: Disabled students'experiences in higher education in Scotland. Studies in Higher Education, 24(2), 183-194. http://dx.doi.org/10.1080/03075079912331379878

Tinklin, T., Riddell, S., \& Willson, A. (2004). Policy and provision for disabled students in higher education in Scotland and England: The current state of play. Studies in Higher Education, 29(5), 637-657. http://dx.doi.org/10.1080/0307507042000261599

West, W. (2002). Some ethical dilemmas in counselling and counselling research. British Journal of Guidance \& Counselling, 30(3), 261-268. http://dx.doi.org/10.1080/0306988021000002308

Yin, R. K. (2003). Case study research: Design and methods. London: Sage.

\section{Copyrights}

Copyright for this article is retained by the author(s), with first publication rights granted to the journal.

This is an open-access article distributed under the terms and conditions of the Creative Commons Attribution license (http://creativecommons.org/licenses/by/3.0/). 